\title{
Wireless Real Time Monitoring and Controlling of Irrigation System
}

\author{
Kushnure Devidas ${ }^{1}$, More Poonam ${ }^{1}$, Padamalakar Dhanashri ${ }^{1}$, Padavale Pooja ${ }^{1}$ \\ Department of Electronics and Telecommunication Engineering, VPKBIET, Baramati, India ${ }^{1}$
}

\begin{abstract}
In this paper we proposed Wireless irrigation monitoring and controlling system to monitor different parameters with the help of wireless sensor network (WSN). The proposed system model which is cost effective and efficient solution for existing irrigation system to monitor real time parameters. The embedded web server is designed using ARDUINO UNO with the help of Real time operating system (RTOS). The system designed using the concept of wireless sensor network and the data collected to the server side is real time and user can continuously monitor and control through the Internet by using computer or handheld wireless devices. The experimental result shows that system useful to monitor and control different parameters from remote location.
\end{abstract}

Keywords: Embedded web server, Free RTOS, LAN, Wireless sensor network.

\section{INTRODUCTION}

The web server concept gives us the flexibility to controlling and monitoring the electronic devices. This work is divided into two phases i.e. hardware and software. The hardware phase consists of server that can connect to Ethernet module and sensor node on which sensors are connected which acquires data according to environmental conditions. For software phase web page enables personal computer to communicate with embedded web server. FreeRTOS is installed in order to get real time response for the system. The sensors data readings are displayed on personal computer and output devices are controlled by accessing the web page. Output devices controlling status can be send on users mobile via gsm module. When user is offline sensor data is stored into memory card [8]. If water level dips, the water pumps may run dry, leading to pump damage. If farmer fails to attend the irrigation, there is chance of wastage of water and electricity [1]. Also, excess watering leads to soil damage. Implementation of drip irrigation system continuously monitored and controlled from remote location far away from actual working station. So that there is proper utilization of water.

In Literature design of web server based on ARM7 processor and ENC28j60 Ethernet controller chip. Through the Ethernet we could acquire the different realtime information, based on this information [4].It is also possible to design Embedded Web Server for Wireless Sensor Network model can continuously display the real time sensor data of Temperature and Humidity on a WSN to the system connected through LAN/Ethernet. And this real time data of Temperature and humidity is wirelessly transferred from sensor node to the embedded web server which can be monitored and further processed [8].It is also possible to connect a micro- controller to LAN or Internet and use it as a web server. This paper offers a new approach to control home appliances from a remote terminal, with an option from a local server, using the Internet [9].

This Paper is organized as follows. The section II, we propose the system using Arduino UNO. In section II, we explain the details of design of the system using embedded web server using Free RTOS. In Section IV, the Practical results shown and conclusion of the paper drawn in section $\mathrm{V}$.

\section{PROPOSED SYSTEM}

The system consists of two parts: 1) Node side 2) Server side. The node side which operates in farm at different locations. This node side is shown in fig. 1. It consists of soil moisture sensor, temperature sensor, LCD display, GSM module and zigbee with Arduino UNO controller.

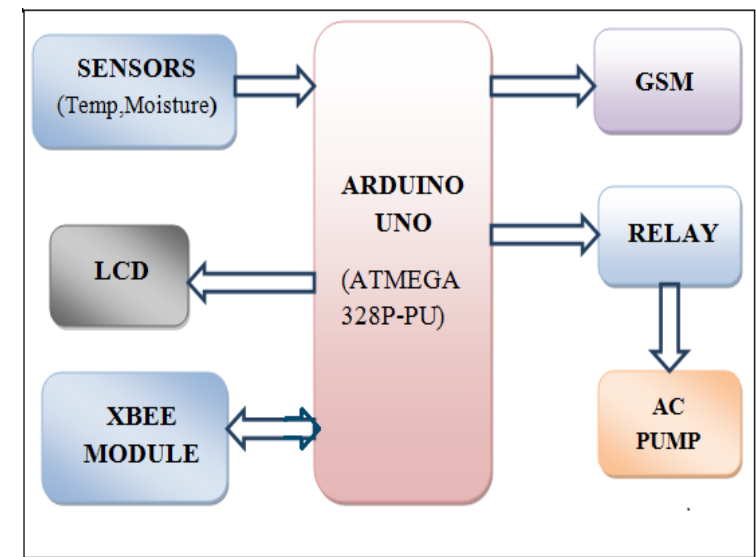

Fig. 1 Wireless Sensor Node

The temperature sensor and soil moisture sensor at node side take the values of temperature and moisture content present in soil and sends it to arduino. These values are 
displayed on LCD. According to sensor's values, motor's status send to the user's mobile phone via GSM. Arduino processes on these values and send it to server using zigbee.

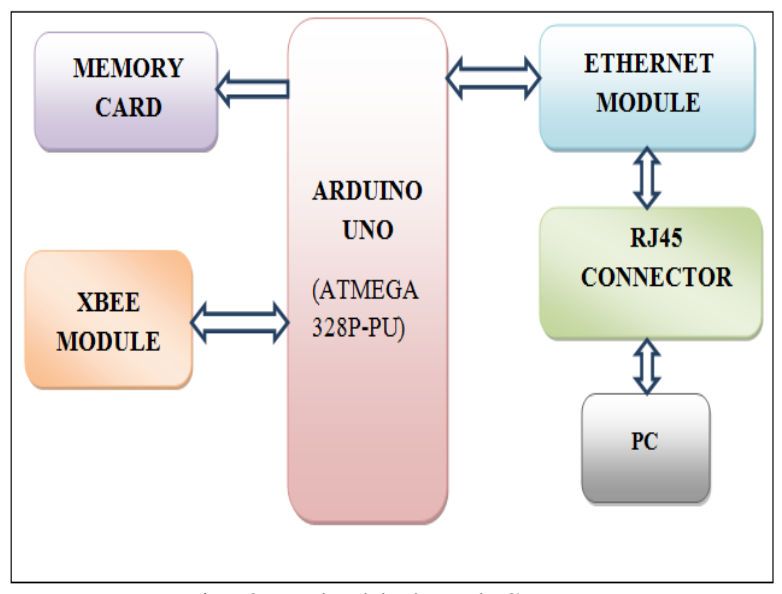

Fig. 2 Embedded Web Server

Embedded web server is shown in fig 2. Server side Arduino takes the same data from zigbee. Arduino communicate to the web server by using Ethernet module. This Ethernet module is connected to the LAN. LAN assigns a unique IP address to Ethernet.By using this IP user can control the output devices at node side. By providing memory card slot the data can be stored into micro SD card when user is offline.

\section{III.DESIGN DETAILS}

A. Embedded Web Server

Embedded Web Server is the hardware component of system that implements the HTTP protocol interfaced with an application. It can be used for controlling and monitoring different system like home automation, industrial applications and agricultural field etc. Ethernet can be easily interfaced with server [8].

B. Wireless Sensor Network

Wireless sensor network consist of several number of nodes. Each node connected to hundred or thousand number of sensors. Each node consists of various parts as follows:

1) Temperature Sensor:LM35 sensor is used to measure the temperature. They are integrated circuit temperature sensors whose output voltage is directly proportional to Celsius Temperature [1].

2) Soil Moisture Sensor: KG003 sensor is used to measure the moisture of soil. It has dual output mode i.e. analog and digital. Analog output is accurate. It operates in the range $3.3 \mathrm{~V}-5 \mathrm{~V}[1]$.

3) Radio Transceiver: Zigbee can be used as radio transceiver. It is used to transfer sensors data wirelessly from node side to server side. Zigbee S1 can be used for transferring the data.
4) Microcontroller: In this project ATMEGA328P-PU Controller is used for controlling actions. It has 28 pins out of which 6 are analog pins and 14 pins are digital. It operates on $5 \mathrm{~V}$ [11].

\section{FreeRTOS}

Most operating systems appear to allow multiple programs to execute at the sametime. This is called multi-tasking. A part of the operating system called the scheduler is responsible for deciding which program to run when, and provides theillusion of simultaneous execution by rapidly switching between each program. A Real Time Operating System is an operating system that is optimized for use in embedded/real time applications [15].

FreeRTOS is a class of RTOS that is designed to be small enough to run on a microcontroller. It enables us to implement multi-tasking. It supports both real-time tasks and co-routines. It provides task notifications, queues, binary semaphores, and counting semaphores. It also provides recursive semaphores and mutexes for communication and synchronization between tasks, or between real time tasks and interrupts. It has a tiny footprint, which is good for boards with limited resources (such as Arduino UNO). It has been designed to be small, simple and easy to use [10].

\section{GSM Technology}

GSM 300 can be used to send message on user's mobile phone. GSM module allows transmission of short message service (SMS) in TEXT mode and PDU mode.

\section{IV.RESULTS}

The experimental setup of system is shown in Fig. 3. In wireless sensor node multiple tasks can be done at a same time. So porting of FreeRTOS is done at node side.

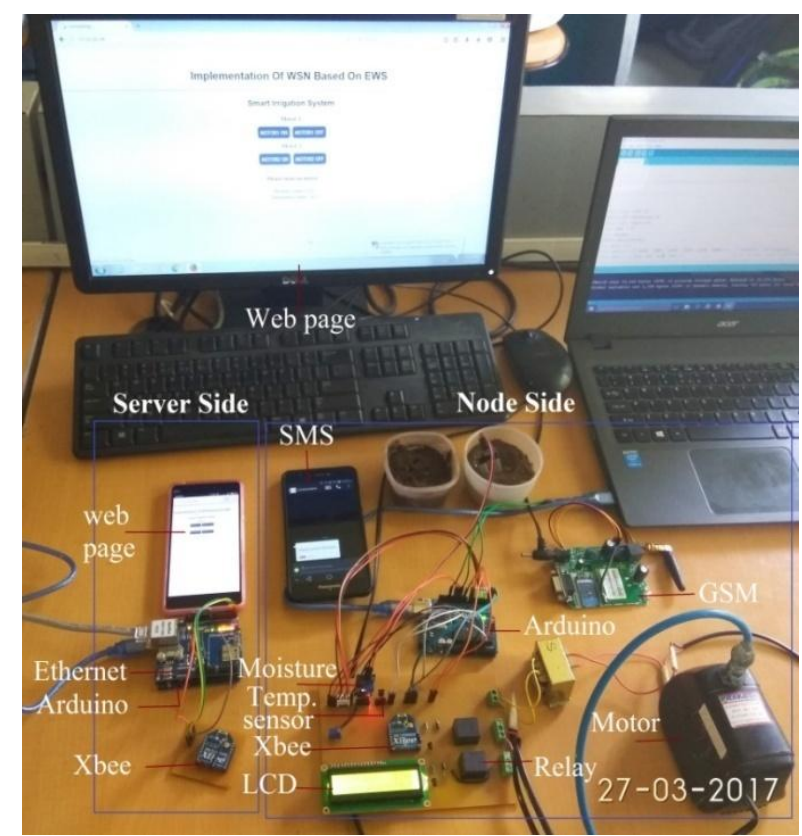

Fig. 3 Experimental Setup 
At server, the arduino with Ethernet shield is connected to the LAN of the network, the power to the board is given through USB connected to PC. Ethernet shield is placed above the arduino board. Zigbee is also interfaced with arduino board.

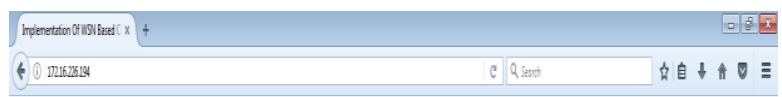

Implementation Of WSN Based On EWS
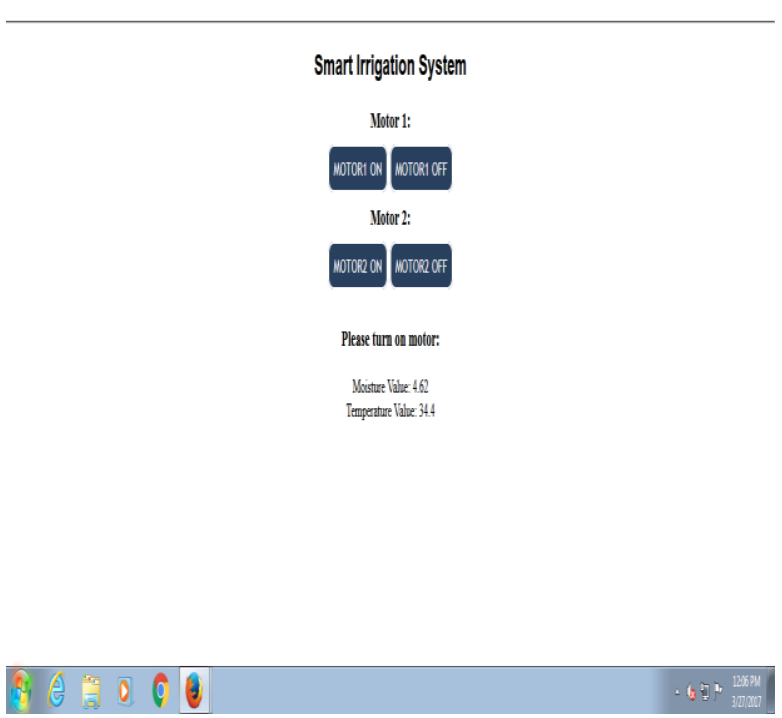

Fig. 4 Web page on computer

The actual web page is shown in Fig. 4 In this web page two buttons are provided for switching of motor at node side. The sensors values and motors status is displayed on web page. By using IP address the web page can be accessed andswitching can be done by user either from PC or Mobilephone.

\begin{tabular}{|c|c|}
\hline PM & K/s O \\
\hline
\end{tabular}

172.16.226.194

Implementation Of WSN Based On EW

Smart Irrigation System

Motor 1:

MOTOR1 ON MOTOR1 OFF
Motor 2:
MOTOR2 ON MOTOR2 OFF

Please turn on motor:

Moisture Value: 4.62

Temperature Value: 34.4

Fig. 5 Web page on mobile

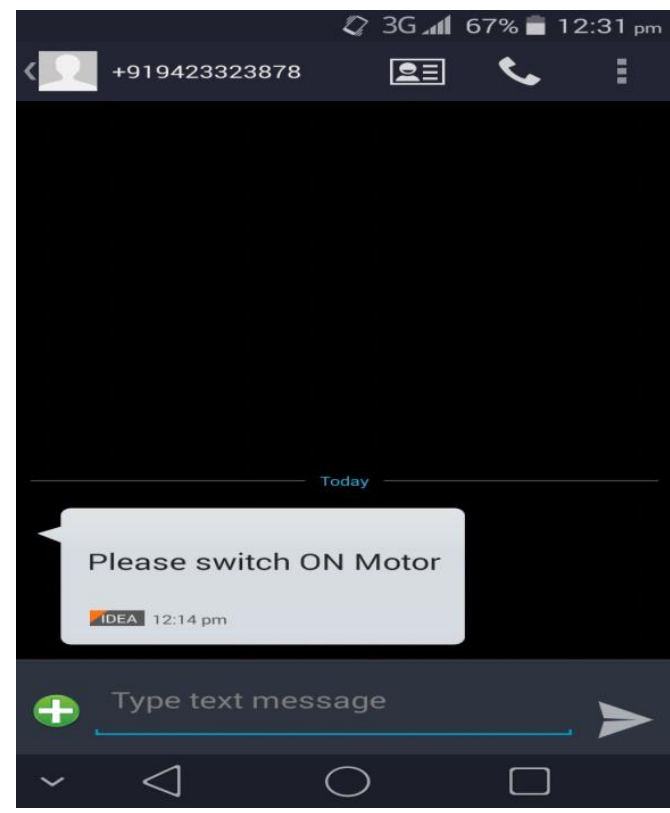

Fig. 6 SMS on Mobile

V. CONCLUSION

In this paper, we proposed and successfully implemented system for the monitoring and controlling of drip irrigation system. This design consists of a real time remote monitoring system using arduino controller and xbee also it is possible to monitor through the mobile phones and computer systems. We have monitored different parameters like temperature and moisture by using sensors and the real time data of temperature and moisture is wirelessly transferred from sensor node to the web server which can be monitored and further processed to take Appropriate action from user side. The model prepared here for demonstration purpose one can extend this on a mass level by using high end embedded servers along with wireless sensor networks and can sense more parameters like moisture, temperature, water flow, water level, rain water indicator, smoke detector etc. Hence the experimental result shows that the proposed model can work in practical environment. It can be used practically to reduce the labour cost and human intervention for water utilization.

Therefore the system demonstrated here is general purpose system hence it can serve for domestic as well as industrial purpose.

\section{ACKNOWLEDGMENT}

Authors would like to thank Department of Electronics and Telecommunication Engineering for providing support and infrastructure to complete the project work.

\section{REFERENCES}

[1] Tasneem Sanglikar and Puranik V.G.,"Design and implementation of automated irrigation control system using WSN:An overview" ,IJRITCC, ISSN 2321-8169,157-161,vol-4,issue 4,April 2016. 
[2] Chandan Kumar Sahu and Pramitee Behera, "A Low Cost Smart Irrigation Control System”, IEEE sponsored 2nd ICECS, 2015 pp. $1146-1152$.

[3] Harshal Ramtekkar, Divya Meshram, Remote monitoring of process in industry using ARM7 and Wireless Sensor Network, ISSN- 4265- 0578ISSN-4265- 0578 Vol. 16, MAY 2015.

[4] Sushma M. Gawali, Snehal M. Gajbhiye Design of ARM based Embedded Web Server for Agricultural Application, IJCSIT, Vol. 5 (1) , 2014, 354-356.

[5] Nitin M.Patil,Pankaj H. Rangaree,G. M. Asutkar, Energy Efficient Implementation of Wireless Sensor Network System on Embedded Web Server Using ARM7, IJLTET,ISSN: 2278- 621X,Vol. 3 Issue 4 March 2014.

[6] Nagisetty Sasidhar and Monica P.Suresh ,ARM microcontroller based Wireless Industrial Automation System, IJAREEIE,Vol. 3,April 2014.

[7] Ayman M. Hassan, Web Based Irrigation Management for Open Canals using Wireless Sensor Network,ICWISE, pp. 102-107 IEEE 2013.

[8] Mohammed Ismail, Aaquib Junaid, Shibashish Banerjee, Md. Abdul Jabbar, Embedded Web Server for Wireless Sensor Network in Industrial Applications,IJAREEIE, Vol. 2, Issue 8, August 2013.

[9] Mr.Abhishek Vichare,Ms.Shilpa Verma,Embedded Web Server for Home Appliances, (IJERA)ISSN: 2248-9622.March 12.

[10] FreeRTOS Tutorial book and reference manuals[online].Available: http://www.freertos.org/

[11] Arduino Datasheet[online] Available: http://www.arduino.org/products/boards/arduino-uno

[12] Libraries of FreeRtos. Available: https://sourceforge.net/projects/freertos/

[13] Raj Kamal, Embedded Systems Architecture, Programming and Design,Tata McGraw Hill Education Private Limited,2nd Edition,2011.

[14] Raj Kamal, Embedded Systems Architecture, Programming and Design,Tata McGraw Hill Education Private Limited,2nd Edition,2011.

[15] Jean J. Labrosse, $\mu$ C/OS- II ,The Real-Time Kernel, Weston, FL 33326, User's Manual,2nd Edition,2002.

\section{BIOGRAPHIES}

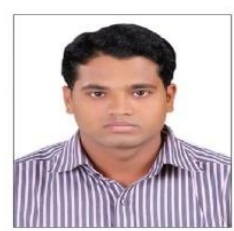

Kushnure Devidas is an Assistant Professor in the department of Electronics and Telecommunication Engineering, VPKBIET Baramati. He has received M.Tech. Degree in Electronics and B.Tech Degree in Electronics and Telecommunication Engineering from S.G.G.S. Institute of Engineering and Technology, Nanded $(\mathrm{MH})$. He has published around 8 research papers in National and International Journals and Conferences his research interests includes Wireless Communication, Digital signal Processing and Digital Image Processing. $\mathrm{He}$ is Life member of ISTE and Member of IEEE.

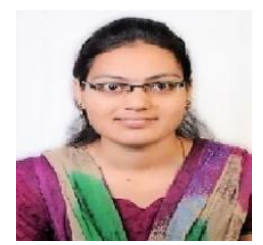

More Poonam is a student in Department of Electronics and Telecommunication, VPKBIET, Baramati, Maharashtra, India. She is currently pursuing her Bachelor's degree in Electronics and Telecommunication Engineering. She is Interested in the Embedded Systems Design and Wireless communication.

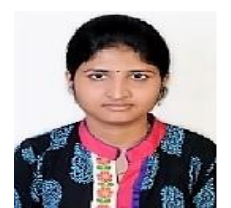

Padamalakar Dhanashri is a student in Department of Electronics and Telecommunication, VPKBIET, Baramati, Maharashtra, India. She is currently pursuing her Bachelor's degree in Electronics and Telecommunication Engineering. She is Interested in the Embedded Systems Design. She is student Member of ISTE.

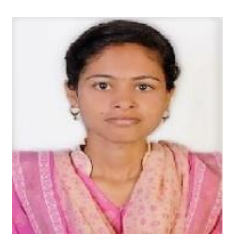

Padavale Poojais a student in Department of Electronics and Telecommunication, VPKBIET, Baramati, Maharashtra, India. She is currently pursuing her Bachelor's degree in Electronics and Telecommunication Engineering. She is Interested in the Real Time Embedded Systems Design. She is student Member of ISTE. 